\title{
Extravasación de medios de contraste intravenosos: Lo que todo radiólogo debe saber
}

\author{
Dres. Cristián Varela $U^{(1)}$, Paulina Sepúlveda $P^{(2)}$, J. Prieto $R^{(3)}$, Sebastián Pavanati $C^{(4)}$.
}

1. Médico Radiólogo. Jefe del Departamento de Imaginología Clínica Dávila. Santiago - Chile.

2. Research Fellow. Departamento de Imaginología Clínica Dávila. Santiago - Chile.

3. Residente de $1^{\circ}$ año de Radiología. Universidad de Los Andes. Santiago - Chile.

4. Alumno $1^{\circ}$ año de Medicina. Universidad de Los Andes. Santiago-Chile.

\section{Extravasation of intravenous contrast media: What every radiologist should know}

Abstract. The accidental release of intravenous contrast media (ICM) from the intravascular compartment to the adjacent soft tissues is one of the most frequent complications of the injection procedure in multi-slice CT (MSCT). Its incidence is low, occurring in between 0.1 and $0.9 \%$ of patients undergoing these studies. Affected areas usually present mild lesions characterized by swelling and local erythema and that tend to resolve spontaneously without sequelae. However, serious lesions may also occur, such as compartment syndrome. For these reasons it is essential to know patients at risk, precautionary measures, specific technical factors, early diagnosis and appropriate management of this complication. These elements constitute basic skills that every radiologist must possess.

Keywords: Contrast media (D003287), Extravasation of diagnostic and therapeutic materials (D005119), Quality control (D011786), Radiology (D011871).

Resumen: La salida accidental de medio de contraste intravenoso $(\mathrm{MCl})$ desde el compartimento intravascular hacia los tejidos de partes blandas adyacentes es una de las complicaciones más frecuentes del procedimiento de inyección en tomografía computada multicorte (TCMC). Su incidencia es baja, ocurre entre el 0,1 y el 0,9\% de los pacientes que se someten a estos estudios. Las zonas afectadas generalmente presentan lesiones leves caracterizadas por aumento de volumen y eritema local que tienden a remitir espontáneamente sin secuelas. Sin embargo, también pueden ocurrir lesiones graves, como un síndrome compartimental. Por estas razones es fundamental conocer los pacientes en riesgo, las medidas de precaución, los factores técnicos específicos, el diagnóstico precoz y el manejo oportuno de esta complicación. Estos elementos constituyen competencias básicas que todo radiólogo debe poseer.

Palabras clave: Control de Calidad(D011786), Extravasación de materiales terapéuticos y diagnósticos (D005119), Medio de contraste (D003287), Radiología (D011871).

Varela C., Sepúlveda P., Prieto J., Pavanati S. Extravasación de medios de contraste intravenosos: Lo que todo radiólogo debe saber. Rev Chil Radiol 2015; 21(4): 151-157.

Correspondencia: Dr. Cristián Varela U. / cvarelaubilla@gmail.com

Trabajo recibido el 06 de agosto de 2015. Aceptado para publicación 18 de noviembre de 2015.

\section{Introducción}

La extravasación de un $\mathrm{MCl}$ se define como la salida accidental de un volumen variable de estas soluciones, desde el compartimento intravascular hacia los tejidos, y compartimentos de partes blandas adyacentes. Este fenómeno sucede durante la inyección de $\mathrm{MCl}$ con bomba mecánica y corresponde a una complicación del procedimiento. Se trata de un evento poco frecuente, pero potencialmente grave dependiendo de la magnitud del volumen extravasado y de las características del paciente afectado.

En este artículo se abordarán los principales as- pectos de esta complicación, ya que el conocimiento acabado y actualizado, especialmente de las medidas de prevención, diagnóstico precoz y manejo constituyen competencias esenciales para la práctica diaria de los radiólogos.

\section{Incidencia}

La extravasación es una de las complicaciones más frecuentes de la inyección intravenosa de MC. Sin embargo, su incidencia es baja, ocurre en aproximadamente el 0,1 a $0,9 \%$ de los pacientes que se someten a estudios de tomografía computada (TC) contrastados ${ }^{(1-3)}$. Chew et 
al, el año 2010 analizó seis series de casos publicados de extravasación de $\mathrm{MCl}$ en TC entre los años 1991 a 2007. Observó que de los 190.656 pacientes, sólo 867 sufrieron extravasaciones, lo que corresponde a una de tasa de incidencia de $0,45 \%(4)$

En resonancia magnética (RM) también ocurren extravasaciones de $\mathrm{MCl}$, pero la incidencia de extravasación de quelatos de gadolinio es aún más baja $(0,05 \%)$, ya que se usan volúmenes más pequeños y la inyección la mayoría de las veces es manual(5).

$\mathrm{El} \mathrm{MCl}$ en base a gadolinio, por otra parte, es menos tóxico para los tejidos afectados, por lo que es excepcional observar efectos nocivos en los pacientes.

En la Unidad de TC de nuestro Departamento de Imaginología, del total de pacientes que se sometieron a estudios contrastados durante los años 2013 y 2014 (27.006 inyecciones), se registraron 49 casos de extravasación de $\mathrm{MCl}$, lo que corresponde a una incidencia anual de $0,09 \%$. Durante este mismo periodo, solo se registró una extravasación de gadolinio.

Cabe mencionar que de todos los casos reportados y registrados en nuestra institución, sólo uno requirió de evaluación por cirugía vascular por presentar síntomas sugerentes de una lesión grave, sin embargo, evolucionó favorablemente y se mantuvo en tratamiento sintomático.

\section{Factores de riesgo}

Los factores de riesgo de extravasación de $\mathrm{MCl}$ se encuentran relacionados con la técnica de inyección y las características del paciente (Tabla I $)^{(1,5)}$.

El uso de inyectoras automáticas de $\mathrm{MCl}$, indispensables en la era del TCMC es un importante factor riesgo de extravasación dados los altos caudales de inyección administrados que pueden vencer fácilmente la resistencia de la pared venosa ${ }^{(3,5-8)}$.

Los catéteres metálicos y de pequeño calibre presentan mayor riesgo de extravasación, ya que pueden

Tabla I. Factores de riesgos asociados a la extravasación de $\mathrm{MCl}$.

Dependientes de la técnica de inyección del MC

- Uso de catéter metálico

- Uso de inyector automático

- Inyección en venas distales y/o pequeñas

- Gran caudal de MC inyectado

- Venas multipuncionadas

- Vía venosa de más de 48 horas

- Falta de supervisión durante la inyección el $\mathrm{MCl}$

Dependientes del paciente

- Incapacidad de comunicación

- Fragilidad vascular o daño en el sistema venoso

- Enfermedades emaciantes

- Edades extremas

- Obesidad lacerar o perforar las paredes venosas. Además, con sus paredes rígidas determinan mayor estrés hemodinámico en el punto de salida de la aguja.

Las vías de teflón o de otros tipos plástico son las recomendadas, ya que ofrecen menos posibilidades de daño vascular local y compliance, lo que reduce el estrés hemodinámico.

Aquellas vías venosas con más de 48 horas de instalación, también se consideran más riesgosas, dada la mayor probablilidad de dislocación, flebitis y/o trombosis focal ${ }^{(8)}$.

Un factor importante también, es el territorio venoso escogido para la inyección. Es recomendable que éste sea en venas del mayor calibre posible (del pliegue del codo hacia craneal) y sin punciones previas ${ }^{(1,3)}$.

Respecto a los factores de riesgo dependientes de los pacientes, se debe considerar que niños pequeños, adultos mayores, personas con trastornos cognitivos o del habla, con nivel de conciencia alterado o bajo el efecto de sedantes, tienen menor capacidad de comunicar síntomas derivados de la extravasación del $\mathrm{MCl}$, durante y/o posterior a la realización del procedimiento, lo que los hace más propensos a presentar mayores volúmenes de extravasación y por ende, mayores complicaciones ${ }^{(5,8)}$.

Pacientes emaciados y con múltiples comorbilidades que impliquen fragilidad venosa deben ser foco de especial atención.

\section{Mecanismos de extravasación}

La extravasación de un $\mathrm{MCl}$ puede ocurrir a consecuencia de diferentes mecanismos.

Uno de ellos consiste en una inadecuada ubicación de la punta del catéter, la que puede encontrarse fuera de la vena o impactada en su pared ${ }^{(8)}$.

También puede producirse mediante la rotura focal de la pared venosa sometida a gran estrés hemodinámico al inyectar a alta presión un gran caudal de medio de contraste, como sucede por ejemplo en los estudios angiográficos.

Otro mecanismo es en el contexto de venas lesionadas por reiteradas punciones, afectadas por flebitis o fenómenos trombóticos, donde la pared ofrecerá soluciones de continuidad, menor complacencia y el lumen mayor resistencia a la inyección ${ }^{(5,8)}$.

Las venas de pequeño calibre (venas distales como las de la muñeca, el tobillo, manos y pies) son frágiles y más susceptibles a rotura y extravasación de $\mathrm{MCl}^{(3,8)}$.

\section{Mecanismos de toxicidad de los medios de contraste intravenosos}

El MCl puede dañar los distintos tejidos o planos anatómicos a los cuales accede una vez extravasado ${ }^{(8)}$. Existen varios mecanismos involucrados, uno de los más importantes corresponde al efecto compresivo o de aumento de presión local en un compartimento pequeño como las manos, muñecas o pies.

La osmolalidad del $\mathrm{MCl}$ es considerada direc- 
tamente proporcional a su toxicidad de manera que las soluciones hiperosmolares tienen mayor riesgo de causar necrosis tisular ${ }^{(8)}$.

La toxicidad intrínseca de las moléculas de los $\mathrm{MCl}$ tiene un mecanismo controvertido que no ha sido bien definido aún, pero se postula que podría existir acción citotóxica directa de los tejidos afectados.

\section{Tipos de extravasaciones}

\section{a) Extravasación subcutánea}

Es la más común y en ella el $\mathrm{MCl}$ diseca al tejido celular subcutáneo. Radiológicamente aparece como una colección de $\mathrm{MCl}$ amorfa, irregular con pequeñas imágenes redondeadas que corresponden a los lobulillos de grasa subcutánea (Figura 1a y 1b).

Tanto el personal de salud que vigila la inyección como el paciente, pueden notar un aumento de volumen adyacente al sitio de punción y un cambio de coloración de la piel, que se enrojece ${ }^{(6)}$.
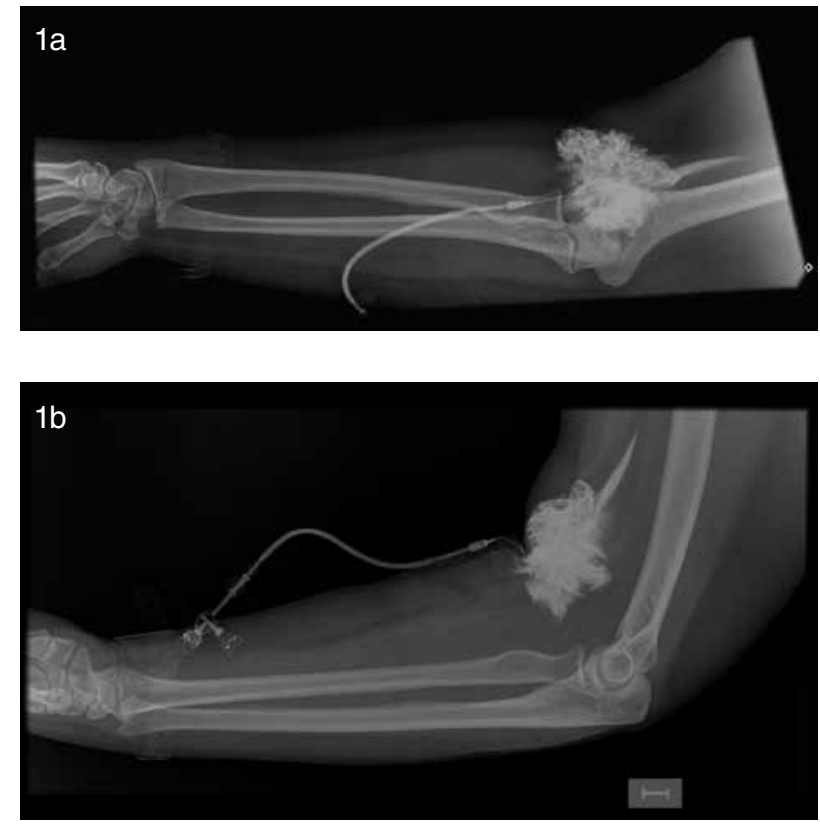

Figura 1a y 1b. Radiografía simple de antebrazo izquierdo. Se observa la vía venosa en el pliegue del codo. Adyacente a ésta, destaca la presencia de una colección de contraste irregular, con imágenes radiolúcidas redondeadas que denota que el $\mathrm{MCl}$ ha disecado el tejido celular subcutáneo.

\section{b) Extravasación subfascial o intracompartimental}

$\mathrm{El} \mathrm{MCl}$ ingresa a planos profundos, subfasciales, dentro de los compartimentos musculares, lo que radiológicamente aparece como una colección de contraste fusiforme bien definida, que delinea los fascículos musculares (Figura $2 a$ y $2 b$ ).

La clínica es atípica, porque no se observa el aumento de volumen superficial característico adyacente al sitio de inyección. El diagnóstico clínico se basa en medir con una huincha el diámetro de la extremidad afectada y compararlo con la contralateral.
Para confirmar este tipo de extravasación es imprescindible realizar una radiografía de la extremidad afectada. Este tipo de extravasación puede producir un aumento súbito de la presión en el espacio anatómico comprometido y dar origen a un síndrome compartimental, el que eventualmente puede ser tratado con fasciotomía quirúrgica(3).

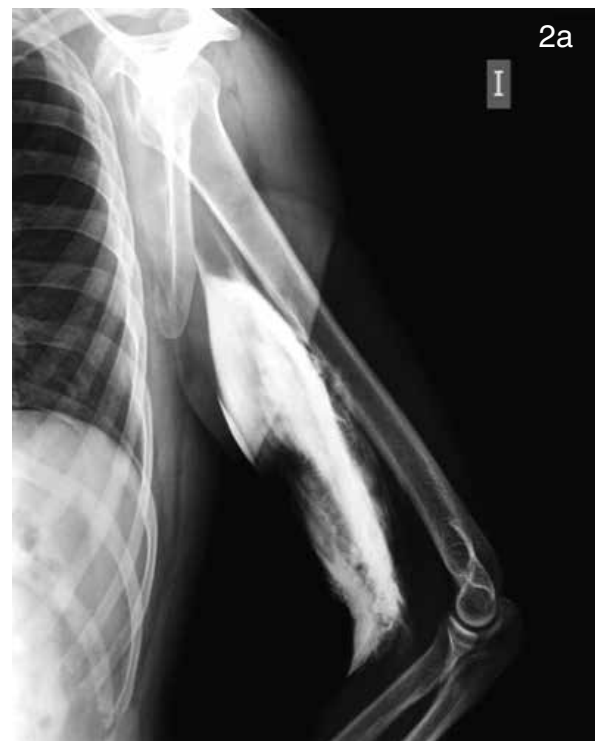

Figura 2a. Radiografía simple de brazo izquierdo. El contraste acumulado tiene una forma de huso, típica de los compartimentos musculares que indica una extravasación subfacial o en el compartimento del músculo bíceps. En el polo inferior de la extravasación, se observa el componente subcutáneo, desde donde ha penetrado hacia los planos profundos.

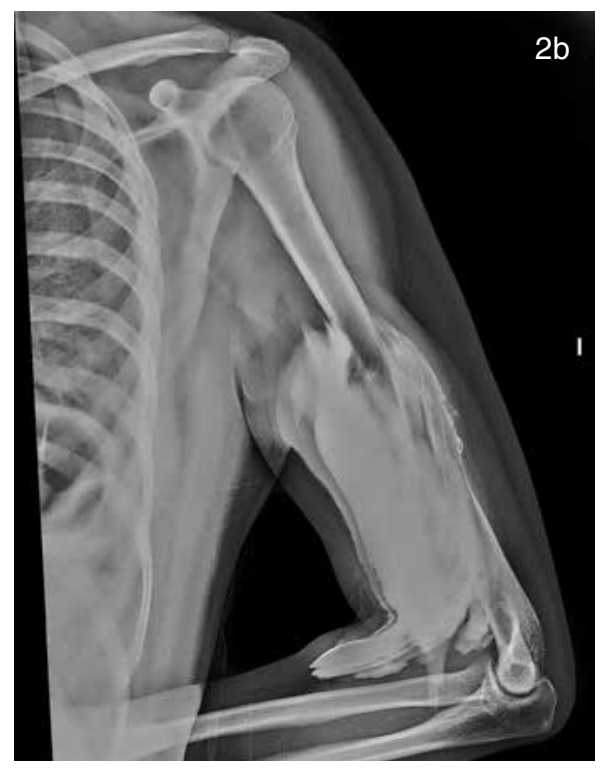

Figura 2b. Radiografía simple de brazo izquierdo. Se observa al igual que en la imagen anterior, la presencia de contraste en el compartimento del músculo bíceps.

\section{c) Extravasación mixta}

Puede observarse una forma mixta con extravasación que diseca el celular subcutáneo y también 
compromete un compartimento muscular vecino (Figura 3).

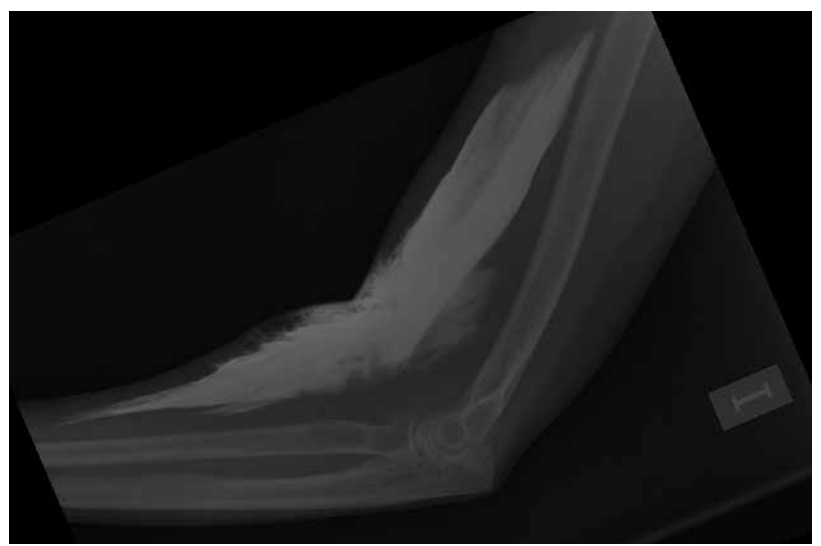

Figura 3. Radiografía simple de brazo y antebrazo derecho. Se observan elementos mixtos, es decir, hay signos de extravasación subcutánea y también compartimental o subfacial. Destacan además, imágenes lineales que representan los fascículos musculares dentro del compartimento del bíceps.

\section{Clínica de la extravasación de $\mathrm{MCI}$}

El diagnóstico de la extravasación de medios contrastados es clínico ${ }^{(5)}$. En general, al momento de extravasación los pacientes suelen referir síntomas tales como: disconfort, dolor, ardor, parestesias, sensación de compresión o rigidez en el sitio de inyección, movilidad disminuida de la extremidad comprometida entre otros ${ }^{(8)}$. Sin embargo, algunos pacientes son asintomáticos y la extravasación se pesquisa por el aumento de volumen que se visualiza y/o palpa en el sitio de inyección o en ocasiones al constatar la ausencia de $\mathrm{MCl}$ en las imágenes del estudio obtenido ${ }^{(5)}$.

En el examen físico lo más común de observar es aumento de volumen superficial en el sitio de inyección que puede acompañarse de discreto eritema, solevantamiento cutáneo adyacente y/o aumento del calor local (Figuras $4 a, 4 b, 5 a$ y $5 b)^{(3,6,8)}$.

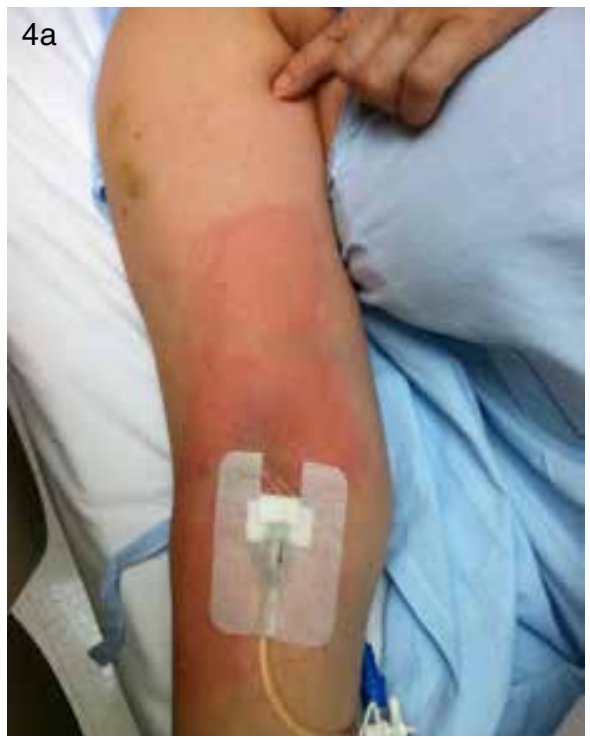

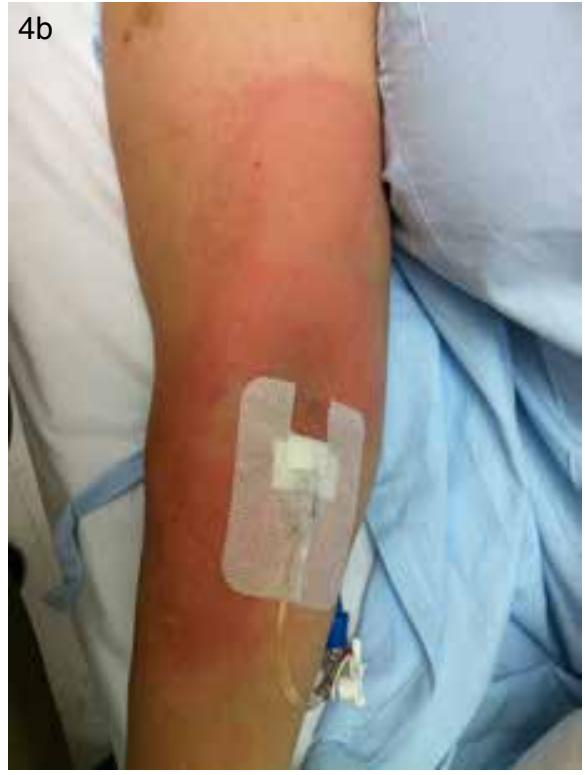

Figuras $4 a$ y $4 b$. Fotos de la extremidad superior de una paciente tras extravasación de $\mathrm{MCl}$. Se observa una vía venosa en el pliegue del codo y adyacente a ella, tanto proximal como distal, existe un eritema asociado a leve solevantamiento de la piel.
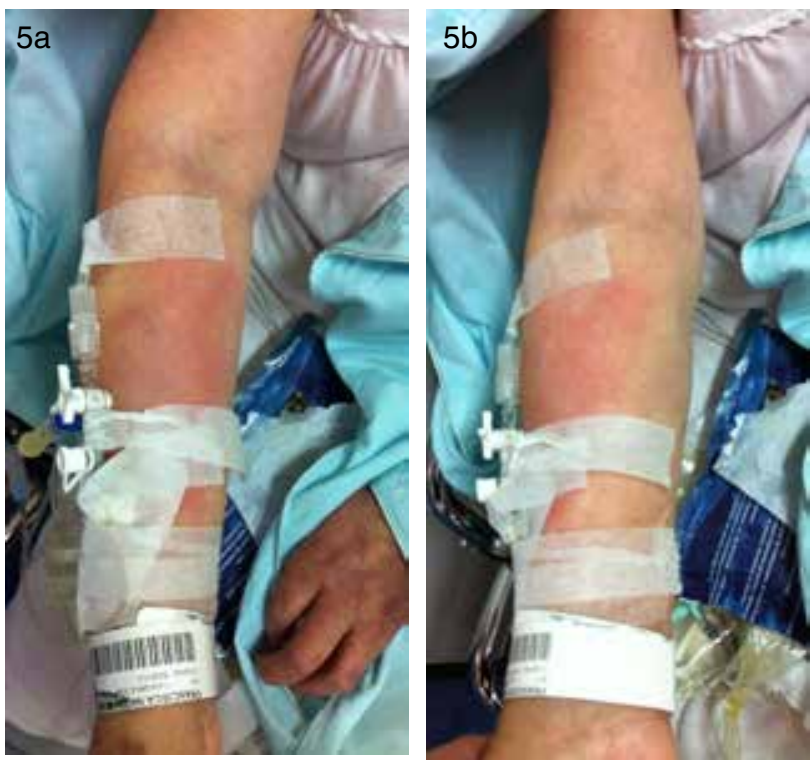

Figura $5 \boldsymbol{a}$ y $\mathbf{5 b}$. Fotos de la extremidad superior de otra paciente tras sufrir extravasación del MCl. Destaca eritema extenso y solevantamiento de la piel adyacente a la vía venosa. La presencia de numerosos parches dificulta el diagnóstico precoz de la extravasación.

Otros casos pueden ser tan graves como un síndrome compartimental en el que tanto el volumen de $\mathrm{MC}$ inyectado como la inflamación secundaria que se genera, ejercen presión sobre los músculos, vasos sanguíneos y nervios, provocando un gran aumento del diámetro de la extremidad afectada, dolor intenso, pérdida de sensibilidad, parestesias, paresia y frialdad cutánea ${ }^{(3,5,6)}$. 
La gran mayoría de estos eventos son limitados al tejido inmediatamente adyacente, típicamente piel y tejido subcutáneo y no suelen causar secuelas permanentes. Sin embargo, hay pacientes con factores de riesgo asociados o comorbilidades que no sólo los hacen propensos a sufrir una extrasación, sino que también a daño por el $\mathrm{MCl}$ (Tabla II).

Tabla II. Factores de riesgo de daño tisular por extravasación de $\mathrm{MCl}$.

Dependientes del MC

- $\mathrm{MCl}$ hiperosmolares

- Grandes volúmenes extravasados (>100 ml)

Dependientes de la técnica de inyección

- Compartimentos pequeños (mano, muñeca pies)

Dependientes del paciente

- Insuficiencia arterial (ateromatosis, DM)

- Insuficiencia venosa

- Insuficiencia linfática

- Enfermedades del colágeno

- Insuficiencia renal

\section{Evolución}

La gran mayoría de los pacientes que sufren una extravasación de un $\mathrm{MCl}$ evolucionarán hacia la resolución espontánea y los síntomas y signos se resolverán entre 24 a 48 horas (Figuras 6 y 7$)^{(1,3,5)}$.
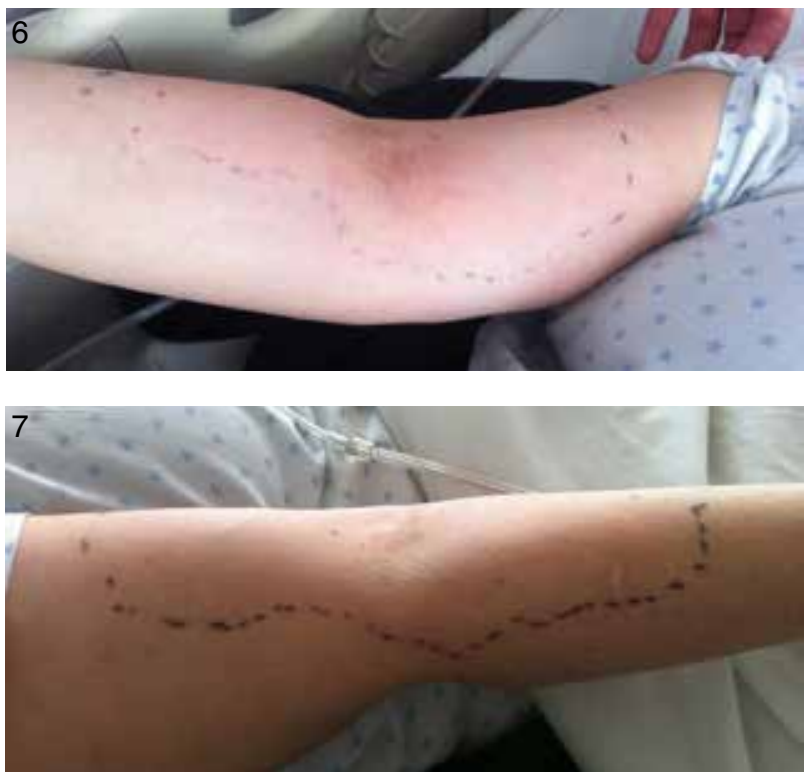

Figuras 6 y 7. Fotos de la extremidad superior de la misma paciente de la Figura 4, veinticuatro horas después de la extravasación. Se observa remisión del eritema y del solevantamiento observado previamente, quedando sólo una pequeña área enrojecida en el pliegue del codo. Destaca la marcación de la piel con un lápiz permanente de la lesión inicial, lo que es útil para evaluar objetivamente su evolución.
Afortunadamente son muy pocos los pacientes que evolucionan desfavorablemente pudiendo presentar lesiones graves como flictenas y ulceración de la piel, necrosis de tejido subcutáneo y/o síndrome compartimental $^{(3,8)}$.

Mientras más grande el volumen de $\mathrm{MCl}$ extravasado y más pequeño sea el compartimento afectado en un paciente con factores de riesgo, mayor será la probabilidad de daño.

\section{Prevención}

Para disminuir la incidencia de esta complicación en pacientes ambulatorios, se deben considerar algunas medidas básicas (Tabla III). Una de las más importantes es realizar una adecuada elección del sitio de inyección, puncionando venas gruesas a partir del pliegue del codo hacia proximal.

Tabla III. Medidas de prevención de extravasación $\mathrm{MCl}$.

Prevención en el paciente ambulatorio

- Adecuada elección del sitio de punción

- Adecuado calibre de catéter

- Uso de vías venosas plásticas

- Inyección vigilada

Prevención en el paciente hospitalizado

- Uso de vía venosa no mayor a 48 horas

- Utilizar un catéter de buen calibre y permeable

- Buscar signos de flebitis

- Instalar una nueva vía venosa frente a flebitis y/o trombosis

- Inyección vigilada

Especial precaución debe tenerse con pacientes que hayan sido sometidas a vaciamiento ganglionar axilar que predispone a daño por extravasación, por ejemplo pacientes operadas de neoplasia mamaria ${ }^{(8)}$.

Se debe escoger un catéter de calibre adecuado para el paciente dependiendo del caudal de inyección. En general se sugieren utilizar catéteres plásticos de 18 a $20 \mathrm{G}^{(1,9)}$.

En pacientes hospitalizados no se recomienda utilizar vías venosas con 48 horas o más de uso ${ }^{(8)}$. Debe verificarse su calibre y permeabilidad. Ante signos de flebitis o evidencias de múltiples punciones es preferible instalar una nueva vía.

Fundamental e irrenunciable es la vigilancia de la vía venosa durante la inyección del $\mathrm{MCI}^{(8)}$. El técnico encargado de ello, deberá palpar el sitio de punción hasta el final de la inyección y en caso de producirse extravasación se detendrá inmediatamente la inyectora.

En la última década se han desarrollado dos avances tecnológicos que disminuyen la probabilidad de que ocurra una extravasación. Una de estas son las vías venosas multifenestradas que no sólo tienen un 
orificio de salida en el extremo distal del catéter, sino también múltiples orificios laterales. Las fenestraciones laterales actúan disminuyendo la velocidad del flujo del $\mathrm{MCl}$, de esta forma reducen el estrés hemodinámico sobre las paredes venosas ${ }^{(9,10)}$.

Otro avance es el desarrollo y uso de dispositivos de detección automática de extravasación como los parches tetrapolares que se colocan en el sitio de la inyección y que miden la impedancia local. Frente a cambios de impedancia provocados por extravasación detienen en forma autónoma la inyectora ${ }^{(11)}$.

\section{Manejo}

Actualmente existe consenso en que el manejo de la extravasación de $\mathrm{MCl}$ debe ser conservador ${ }^{(6)}$. Cada
Departamento de Imágenes que realiza inyecciones de $\mathrm{MCl}$ debe contar con un protocolo de actuación y manejo (Figura 8). Tomando en cuenta las recomendaciones de las distintas guías internacionales y de la propia experiencia de nuestro Departamento de Imaginología, se sugiere:

1) Tras la pesquisa de la extravasación del $\mathrm{MCl}$ debe detenerse la inyección y retirar la vía venosa, al mismo tiempo en que se aspira suavemente, para intentar extraer la mayor cantidad posible de contraste adyacente al catéter.

2) Una vez realizado lo anterior, se recomienda delimitar en la piel con lápiz permanente la extensión del aumento de volumen o eritema, para evaluar la evolución temporal de la lesión.

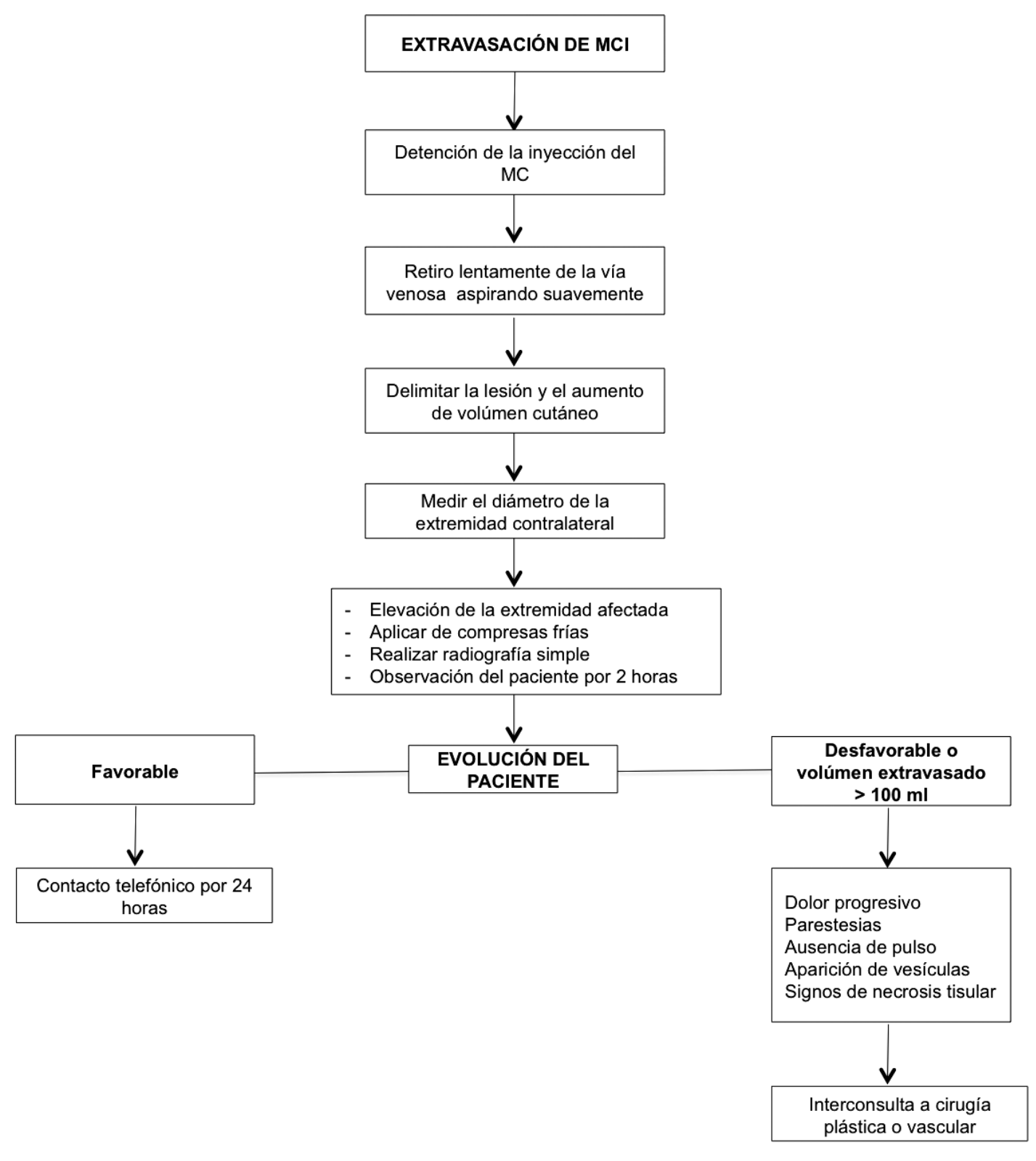

Figura 8. Algoritmo de manejo de una extravasación de $\mathrm{MCl}$ en nuestro centro. 
3) En algunos casos, en los que la extravasación ocurre en compartimientos profundos es de utilidad medir el diámetro de la extremidad afectada y compararla con la contralateral.

4) Recomendamos el uso de la radiografía simple de la extremidad afectada, ya que permite verificar la presencia del $\mathrm{MCl}$ en alguno de los compartimentos posibles (tipos de extravasación), así como también permite una mejor estimación del volumen extravasado.

5) A continuación se debe proceder a elevar la extremidad afectada a un nivel igual o mayor que la altura del corazón, lo que permite disminuir la presión hidrostática capilar, y por consecuencia facilitar la reabsorción desde los tejidos afectados y drenaje del $\mathrm{MCl}$ extravasado en conjunto con el edema que acompaña a cualquier respuesta inflamatoria.

6) Aplicar frío local en forma de compresas húmedas, bolsa de hielo o gel congelado que alivia los síntomas. Teóricamente, produce vasoconstricción disminuyendo la inflamación y dolor del paciente. Otros autores, recomiendan aplicación tópica de calor para promover vasodilatación y reabsorción del $\mathrm{MCl}$, no tenemos experiencia en esta alternativa.

7) Posteriormente, en pacientes hospitalizados se debe registrar la complicación en la ficha clínica del paciente y contactar al médico tratante y/o personal de salud a cargo para informarlos y dar instrucciones de manejo.

8) En pacientes ambulatorios se debe observar al paciente por al menos 2 horas y mantener un contacto telefónico por al menos 24 horas tras ocurrida la extravasación, enseñando signos y síntomas de alarma para consultar al servicio de urgencias.

9) Se recomienda realizar una interconsulta a cirugía plástica frente a la sospecha de una complicación en evolución o preventivamente en casos de extravasación de volúmenes iguales o mayores a 100 $\mathrm{ml}$ de $\mathrm{MCl}$.

\section{Conclusiones}

La extravasación de medios de contraste yodados en TC es una complicación poco frecuente pero de curso favorable, sin embargo, puede evolucionar a lesiones graves, por lo que es de gran relevancia su conocimiento, prevención, detección y manejo oportuno por parte de los radiólogos y el personal que trabaja en los Departamentos de Imaginología.

\section{Bibliografía}

1. Wienbeck S, Fischbach R, Kloska SP, Seidensticker
P, Osada N, Heindel W, et al. Prospective Study of Access Site Complications of Automated Contrast Injection With Peripheral Venous Access in MDCT. Am J Roentgenol 2010 Oct 1; 195(4): 825-829.

2. Bellin M-F, Jakobsen JÅ, Tomassin I, Thomsen HS, Morcos SK, (esur) members of the *Contrast MSC of the ES of UR. Contrast medium extravasation injury: guidelines for prevention and management. Eur Radiol 2002 Nov; 12(11): 2807-2812.

3. Wang $\mathrm{CL}$, Cohan $\mathrm{RH}$, Ellis JH, Adusumilli S, Dunnick NR. Frequency, Management, and Outcome of Extravasation of Nonionic lodinated Contrast Medium in 69657 Intravenous Injections. Radiology 2007 Apr 1; 243(1): 80-87.

4. Chew FS. Extravasation of lodinated Contrast Medium During CT: Self-Assessment Module. Am J Roentgenol 2010 Dec 1; 195(6suppl): S80-85.

5. Pacheco FJ, Gago B, Méndez C. Extravasation of contrast media at the puncture site: Strategies for managment. Radiología 2014 Aug; 56(4): 295-302.

6. Sbitany H, Koltz PF, Mays C, Girotto JA, Langstein $H N$. CT contrast extravasation in the upper extremity: Strategies for management. Int J Surg 2010; 8(5): 384-386.

7. Namasivayam S, Kalra MK, Torres WE, Small WC. Adverse reactions to intravenous iodinated contrast media: an update. Curr Probl Diagn Radiol 2006 Aug; 35(4): 164-169.

8. Cohan RH, Ellis JH, Garner WL. Extravasation of radiographic contrast material: recognition, prevention, and treatment. Radiology 1996 Sep; 200(3): 593-604.

9. Johnson PT, Christensen GM, Fishman EK. I.v. contrast administration with dual source 128-MDCT: a randomized controlled study comparing 18-gauge nonfenestrated and 20-gauge fenestrated catheters for catheter placement success, infusion rate, image quality, and complications. AJR Am J Roentgenol 2014 Jun; 202(6): 1166-1170.

10. Marin D, Nelson RC, Rubin GD, Schindera ST. Body CT: Technical Advances for Improving Safety. Am J Roentgenol 2011 Jul 1; 197(1): 33-41.

11. Powell CC, Li J ming, Rodino L, Anderson FA. A New Device to Limit Extravasation During ContrastEnhanced CT. Am J Roentgenol 2000 Feb 1; 174(2): 315-318.

Guías clínicas de referencia

1. American College of Radiology, Manual on Contrast Media. Version 9, 2013. Disponible en: http://www. acr.org/quality-safety/resources/contrast-manual

2. ESUR 8.1 Contrast Media Guidelines. Disponible en: http://www.esur.org/guidelines/

3. Guías clínicas sobre el uso de medios de contraste intravascular. Sociedad Chilena de Radiología, guía clínica no5: "Prevención y manejo de la extravasación de medios de contraste". Disponible en: www.sochradi.cl 